\title{
Making a Difference Matters: Impact Unlocks the Emotional Benefits of Prosocial Spending
}

\section{Citation}

Aknin, Lara B., Elizabeth W. Dunn, Ashley V. Whillans, Adam M. Grant, and Michael I. Norton. "Making a Difference Matters: Impact Unlocks the Emotional Benefits of Prosocial Spending." Journal of Economic Behavior \& Organization 88 (April 2013): 90-95.

\section{Published Version}

http://dx.doi.org/10.1016/j.jebo.2013.01.008

\section{Permanent link}

http://nrs.harvard.edu/urn-3:HUL.InstRepos:11320613

\section{Terms of Use}

This article was downloaded from Harvard University's DASH repository, and is made available under the terms and conditions applicable to Open Access Policy Articles, as set forth at http:// nrs.harvard.edu/urn-3:HUL.InstRepos:dash.current.terms-of-use\#OAP

\section{Share Your Story}

The Harvard community has made this article openly available.

Please share how this access benefits you. Submit a story.

Accessibility 
Making a Difference Matters: Impact Unlocks the Emotional Benefits of Prosocial Spending

Lara B. Aknin

Simon Fraser University

Elizabeth W. Dunn, Ashley V. Whillans

University of British Columbia

Adam M. Grant

Wharton Business School

Michael I. Norton

Harvard Business School

WORD COUNT: 2,914

CORRESPONDING AUTHOR:

Lara Aknin

laknin@sfu.ca

Department of Psychology

Simon Fraser University

8888 University Drive, Burnaby, BC V5A 1S6

CANADA

Phone: 604-729-9571 Fax: 778-782-3427 


\begin{abstract}
When does giving lead to happiness? Here, we present two studies demonstrating that the emotional benefits of spending money on others (prosocial spending) are unleashed when givers are aware of their positive impact. In Study 1, an experiment using real charitable appeals, giving more money to charity led to higher levels of happiness only when participants gave to causes that explained how these funds are used to make a difference in the life of a recipient. In Study 2, participants were asked to reflect upon a time they spent money on themselves or on others in a way that either had a positive impact or had no impact. Participants who recalled a time they spent on others that had a positive impact were happiest. Together, these results suggest that highlighting the impact of prosocial spending can increase the emotional rewards of giving.
\end{abstract} Keywords: Prosocial spending, prosocial impact, subjective well-being, happiness, donations 
Giving often feels good. A growing body of research demonstrates that using time and money to benefit others has emotional rewards for the giver. For instance, Lyubomirsky, Sheldon and Schkade (2005) report that participants assigned to commit five acts of kindness on one day a week for six weeks were happier than participants assigned to a no-action control group (see also Penner, Dovidio, Piliavin, \& Schroeder, 2005). Similarly, spending money on others leads to higher levels of happiness than spending money on oneself in North America and around the world (Aknin et al., 2012; Dunn, Aknin, \& Norton, 2008). Even toddlers display greater happiness when giving rather than receiving (Aknin, Hamlin, \& Dunn, 2012).

Despite the seemingly ubiquitous relationship between giving and emotional benefits, prosocial acts do not always increase happiness (e.g., Weinstein \& Ryan, 2010; Williamson \& Clark, 1989). For example, Weinstein and Ryan (2010) found that the emotional benefits of helping were eliminated when helpers were instructed that they "should" help; thus, personal volition seems critical for experiencing the happiness rewards of giving. While autonomous motivation is one moderator, we explore whether prosocial impact - feeling as if one has made a positive impact on others - is another catalyst for turning good deeds into good feelings. Research on self-efficacy demonstrates the importance of successfully completing actions - from personal goals to assembling furniture - to derive well-being through feelings of competence and control (Bandura, 1977; Deci \& Ryan, 2000; Norton, Mochon, \& Ariely, 2012; Ryan \& Deci, 2000; White, 1959). We suggest that trying to help someone and having an impact on that person fulfills the human desire to effectively enact goals. In turn, we argue that prosocial impact marks effective prosocial behavior and should moderate the emotional rewards of giving.

While research has not tested whether prosocial impact is important for experiencing the emotional benefits of giving, three independent lines of research suggest that impact is a 
predictor of engaging in prosocial behavior. Research on empathic joy shows that participants who adopt the perspective of someone in need are more likely to offer help to that individual if they believe they will receive feedback about their assistance (Smith, Keating, \& Stotland, 1989). Research on the identifiable victim effect documents the disparity between how much assistance people are willing to provide identifiable victims over equal numbers of unidentified cases (e.g., Jenni \& Loewenstein, 1997; Small \& Loewenstein, 2003), perhaps because helping a particular person facilitates helpers' ability to imagine the difference their efforts will make. Finally, experiencing a sense of prosocial impact leads to subsequent helping behaviour (Grant, 2008; Grant et al., 2007). In one study, students who received a thank-you note from a recipient were more likely to offer additional help to this recipient and to others (Grant \& Gino, 2010).

In contrast to research demonstrating that prosocial impact is an antecedent of prosocial behavior, we explore the emotional consequences of engaging in impactful prosocial behavior. Specifically, we predicted that prosocial impact would moderate the happiness induced by giving because receiving knowledge about one's impact offers evidence that one's efforts have been effective (Deci \& Ryan, 2000; Ryan \& Deci, 2000).

\section{Overview}

Two experiments examine whether the emotional rewards of giving are greatest when givers are aware of their positive impact. In Study 1, we model instances of charitable giving by offering participants the opportunity to donate to one of two real charities that improve living conditions for children around the world: the United Nations International Children's Emergency Fund (UNICEF), which funds a variety of child health care initiatives, or an affiliated organization Spread the Net (SPN), which focuses on buying bed nets to stop the spread of malaria. While both charities assist children in need, their aims and appeals differ. UNICEF 
advertises the range of their initiatives, while SPN advertises the substantial impact of purchasing one bed net for a child in Africa. Using these different appeals allows us to examine whether donors experience higher subjective well-being after giving to a charity that emphasizes the impact of a donor's spending. In Study 2, we tighten experimental control and use a recollection design to probe whether impactful instances of prosocial spending lead to higher happiness than low-impact prosocial spending or spending on oneself. Together, these experiments build upon previous research, looking beyond whether prosocial impact encourages prosocial behavior to focus on whether prosocial impact unlocks the emotional rewards of giving.

Across studies, we measured the broad construct of subjective well-being (SWB) using multiple scales (see Diener \& Biswas-Diener, 2002; Kashdan, Biswas-Diener, \& King, 2008). To maximize the breadth of our measures and the brevity of our paper, we standardized and averaged each scale to create composite SWB measures, which are reported in text. In line with recent guidelines for maximizing transparency (Simmons, Nelson \& Simonsohn, 2011), we report results on each scale in the Supplementary Materials.

Study 1

Method

\section{Participants and Procedure}

One-hundred twenty individuals ( $60 \%$ female; $\left.M_{a g e}=21.4, S D=3.5\right)$ on the University of British Columbia campus completed a study on charitable appeals in exchange for ten dollars. After providing consent, participants were paid, asked to sign a receipt for payment, and told to put their payment away. Participants then reported their general happiness on a single-item 
measure (Abdel-Khalek, 2006) and an abbreviated 2-item version of the Subjective Happiness Scale ( $\alpha=.84$; Lyubomirsky \& Lepper, 1999). Participants were presented with a print ad for UNICEF. While examining the ad, participants were randomly assigned to one of two conditions (UNICEF or SPN) by a research assistant blind to our hypotheses (Table 1). Participants were told that the lab was collecting money for this cause, and asked if they would like to donate. If they agreed, the assistant collected the donation, and recorded their name and donation amount.

Participants then reported their SWB on a cognitive and affective measure; current positive affect was reported on the Positive and Negative Affect Schedule, which included the word "happy" (PANAS; 1-very slightly or not at all to 5-extremely; $\alpha=.89$ for 11-item scale; Watson, Clark, \& Tellegen, 1988), and overall cognitive evaluation of life on the Satisfaction With Life Scale (SWLS; 1-strongly disagree to 7-strongly agree; $\alpha=.85$; Diener, Emmons, Larson, \& Griffin, 1985).

Participants also completed a five-item measure of perceived prosocial impact to assess whether they felt they had made a positive, meaningful, or significant change for someone else (1-not at all to 7-very much; $\alpha=.97 ;$ Grant et al., 2007).

\section{Results}

\section{Donation rates}

Donation rates did not differ between the two conditions. Participants gave roughly five dollars to UNICEF $(M=5.44, S D=4.11)$ and SPN $(M=5.07, S D=4.39), F(1,118)=.22, n s$. 


\section{Manipulation check}

Prosocial impact ratings were higher in the SPN condition $(M=4.32, S D=2.01)$ than in the UNICEF condition $(M=3.57, S D=1.54), t(117)=2.30, p<.03$, suggesting that the charitable appeals distinguished between high and low impact giving opportunities.

\section{Emotional benefits of giving}

The two baseline measures of SWB were significantly correlated, $r(120)=.64, p<.001$, as were the two measures of post-donation SWB , $r(118)=.32, p<.001$. As such, overall means on the two scales were standardized and combined to create broad measures of pre- and postdonation SWB. Using these composites, we examined whether condition influenced the hedonic rewards of giving by entering baseline happiness, donation amount (mean centered to zero), condition assignment $(-1=\mathrm{UNICEF}, 1=\mathrm{SPN})$ and a ConditionXDonation interaction term into a regression equation predicting post-donation well-being.

Not surprisingly, baseline well-being predicted post-donation $\operatorname{SWB}(\beta=.58, p<.001)$ as did larger donations $(\beta=.15, p=.051)$. The effect of condition was not significant $(\beta=-.04, p=$ $.61)$, but the ConditionXDonation interaction $(\beta=.15, p<.05)$ predicted post-donation wellbeing, suggesting that the relationship between donation size and SWB depends upon whether the donation was given to UNICEF or SPN. Probing this interaction, we examined the relationship between donation size and well-being in the two conditions separately. Using baseline well-being and donation to predict post-donation SWB for each condition, analyses revealed that larger donations predicted higher SWB when participants gave to SPN $(\beta=0.29, p$ $<.01)$, but not when giving to UNICEF $(\beta=0.00, n s)$. Thus, giving more money to charity 
predicted higher SWB only when participants donated to a charity that provided information about how their donation would make a positive impact (Figure 1).

\section{Discussion}

These results suggest that the emotional benefits of giving may depend on the extent to which donors are presented with information about how their donation impacts recipients. Participants offering larger donations to charity experienced higher happiness, but only when donations were given to SPN - a charity that clearly identified how donations would be used to help recipients. This effect occurred beyond baseline happiness - suggesting that the relationship between happiness and donation size was not a result of pre-existing well-being differences.

Study 1 was designed to maximize external validity and thus we presented participants with the language used by real charities to encourage donations. This strategy allowed us to demonstrate that people experience very different emotional rewards from giving to charities with similar missions (helping needy children). Remarkably, we found that people who donated more money to one of the world's best known charities, UNICEF, failed to reap any emotional benefits from their generosity. Yet, people who donated more money to an affiliated charity (SPN) that highlights perceived impact did report greater happiness. These findings underscore the potential real-world importance of maximizing prosocial impact, but because we used real charitable appeals, the ads differed along multiple dimensions other than impact (e.g., specificity of beneficiary). Thus, while Study 1 is consistent with the hypothesis that prosocial impact moderates the emotional benefits of generosity, a controlled experiment is necessary to confirm that differences in prosocial impact cause differences in the emotional benefits of prosocial spending. This was the goal of Study 2, which used a spending recollection paradigm; this strategy has been utilized successfully in previous research studying the emotional consequences 
of real-world spending (e.g., Van Boven \& Gilovich, 2003).

Whereas Study 1 allowed participants to donate to charities offering high and low levels of impact, some participants in Study 2 recalled an instance in which their prosocial purchase had no impact. Therefore, in Study 2, we predicted that participants would report the highest happiness after recalling a time they spent money on others when their donation had positive impact on the recipient.

Study 2

Method

\section{Participants and Procedure}

One-hundred eighty-one individuals (69\% female) were recruited for monetary payment on Amazon's Mechanical Turk system. Participants were predominantly from the United States (85.1\%), with additional participants from Canada (2.2\%), Ecuador (0.6\%), Mexico (0.6\%), and unknown locations $(11.6 \%)$.

Participants were randomly assigned to one of three conditions ${ }^{1}$ in which they vividly recalled the last time they spent approximately twenty dollars on: themselves (personal), someone else in a way that had a meaningful impact on that person (prosocial boost), or someone else but the purchase did not have an impact on that person (prosocial blocked). Afterward, participants reported their current affect on the PANAS ( $\alpha=.90$; Watson et al., 1988), their life satisfaction on the SWLS $(\alpha=.93$; Diener et al., 1985) and completed the same measure of perceived prosocial impact used in Study 1 ( $\alpha=.97$; Grant et al., 2007). 


\section{Results}

\section{Manipulation check}

We predicted that prosocial impact ratings would differ across the three recollection conditions, such that participants assigned to the prosocial boost condition would report the highest levels of prosocial impact, followed by participants in the prosocial blocked and then personal spending conditions. A one-way ANOVA supported this hypothesis, $F(2,174)=$ 104.52, $p<.001$, as did Fisher's LSD post-hoc contrasts (see Table 2).

\section{Subjective Well-being}

Consistent with Study 1, the two SWB measures were significantly correlated $r(181)=$ $.29, p<.001$, so the two scales were standardized and combined to create one measure of SWB. Using this measure, we conducted a one-way ANOVA comparing the well-being of participants. The overall analysis revealed a significant effect $F(2,178)=4.18, p<.02$, and Fisher's LSD contrasts revealed that participants in the prosocial boost condition reported higher SWB than participants in the other two conditions, while SWB levels in the personal and prosocial blocked conditions did not differ (Table 2). Thus, recalling a previous prosocial spending experience led to the highest SWB when participants recalled a time that their spending had a positive impact on the recipient.

\section{Discussion}

Study 2 provides additional support for the hypothesis that prosocial impact moderates the emotional benefits of prosocial spending. Participants assigned to recall a time they spent on others in way that had positive impact reported higher well-being than participants who recalled 
a time they spent on someone else but did not have an impact, and participants who recalled a time they spent on themselves. These results provide a conceptual replication of Study 1 with a more tightly-controlled recollection paradigm.

\section{General Discussion}

Two studies suggest that prosocial impact unleashes the emotional rewards of giving. In Study 1, giving more money to charity led to higher levels of well-being only when donations were given to SPN - a charity that clearly identified how donations were used to help recipients. Similarly, in Study 2, participants assigned to recall a previous spending experience reported the highest levels of happiness after reflecting upon a time they spent on others and had an impact.

Whereas Study 1 was designed to maximize external validity, Study 2 was designed to maximize internal validity. In Study 1, we used a real charitable appeal that did not provide donors with any information about how exactly their gift would be used, leaving the impact of their donation ambiguous. In Study 2, we specified that participants in the prosocial-blocked condition should recall a time when their generous spending did not have an impact, thereby eliminating ambiguity and tightening experimental control. Although the degree of impact was left ambiguous in the UNICEF condition of Study 1 and eliminated in the prosocial-blocked condition of Study 2, the results across studies were remarkably similar; participants who gave more money to UNICEF experienced no measurable happiness payoff relative to those who kept more of their payment for themselves, and participants in the prosocial-blocked condition experienced no greater happiness relative to those who recalled spending money on themselves. Taken together, these studies provide initial evidence that failing to provide information about impact may be akin to failing to have an impact in terms of the emotional consequences for donors. 
These findings extend previous research by documenting an important catalyst for the emotional benefits of giving: helping is most likely to lead to happiness when helpers know they have assisted another person in a meaningful way. These findings also offer a new framework for understanding varied support for the emotional benefits of prosocial behavior. While past research has presented mixed results for the relationship between giving and happiness - with kind actions sometimes increasing happiness and other times not - we present evidence suggesting that prosocial behavior is most likely to produce hedonic gains when helpers are aware of their effective assistance.

The present work underscores the importance of impact in unleashing the emotional rewards of giving, though we note that our results are from a sample of predominantly North American participants. Recent research suggests that the benefits of generous spending on wellbeing generalize to other countries around the world - from Canada to Uganda to South Africa (Aknin et al., 2012) - but future research should explore whether factors that increase the "giving-happiness" link vary meaningfully between cultures. Whereas the current results suggest that perceived impact is a key contributor in producing happiness among North American givers, impact may play a different role in other cultures, where both forms and norms of giving vary widely. For example, the frequency with which recipients acknowledge the impact that a giver's prosocial spending has had may make generous spending more rewarding in some cultures than others.

In contrast to results reported in identifiable victim effect experiments, participants in Study 1 did not offer larger donations to the high impact cause. This may have occurred because of several methodological features of our experiment, such as the request for an immediate donation and the fixed ten dollar study payment. These results hint toward a promising feature of 
prosocial impact; although the high impact giving conditions of Study 1 were not enough to boost generosity, impact information did unleash the emotional rewards of giving. Hence, even when giving conditions do not increase donations, givers may still experience greater emotional rewards when engaging in more impactful acts of prosocial spending.

Offering donors the opportunity to learn about the impact of their donation may have additional positive downstream consequences. While participants gave equal amounts of money to UNICEF and SPN in Study 1 on average, donating money to SPN provided greater emotional rewards. Previous research suggests that when people experience greater emotional rewards from giving, they are more likely to engage in generous spending in the future; in one study, the happier participants felt after reflecting on a past spending experience, the more likely they were to choose to spend a new windfall on others rather than themselves (Aknin, Dunn, \& Norton, 2011). Thus, impactful acts of prosocial spending might be most likely to inspire larger future donations, initiating a positive feedback loop between giving and happiness. 


\section{References}

Abdel-Khalek, A.M. (2006). Measuring happiness with a single-item scale. Social Behaviour and Personality, 34, 139-150.

Aknin, L. B., Barrington-Leigh, C. P., Dunn, E. W., Helliwell, J. F., Burns, J., Biswas-Diener, R., Kemeza, I., Nyende, P., Ashton-James, C., \& Norton, M. I. (2012). Prosocial spending and well-being: Cross-cultural evidence for a psychological universal. Manuscript under review.

Aknin, L. B., Dunn, E. W., \& Norton, M. I. (2011). Happiness runs in a circular motion: Evidence for a positive feedback loop between prosocial spending and happiness. Journal of Happiness Studies, 13(2), 347-355.

Aknin, L.B., Hamlin, J.K. \& Dunn, E.W. (2012). Giving leads to happiness in young children. PLoS One, 7(6), e39211.

Bandura, A. (1977). Self-efficacy: Toward a unifying theory of behavioral change. Psychological Review, 84, 191-215.

Deci, E. L., \& Ryan, R. M. (2000). The "what" and "why" of goal pursuit: Human needs and the self-determination of behavior. Psychological Inquiry, 11, 227-268.

Diener, E., \& Biswas-Diener, R. (2002). Will money increase subjective well-being? Social Indicators Research, 57, 119-169.

Diener, E., Emmons, R. A., Larson, R. J., Griffin, S. (1985). The Satisfaction with Life Scale. Journal of Personality Assessment, 49, 71-75.

Dunn, E. W., Aknin, L. B., \& Norton, M. I. (2008). Spending money on others promotes happiness. Science, 319, 1687-1688. 
Grant, A. M. (2008). The significance of task significance: Job performance effects, relational mechanisms, and boundary conditions. Journal of Applied Psychology, 93, 108-124.

Grant, A. M., Campbell, E. M., Chen, G., Cottone, K., Lapedis, D., \& Lee, K. (2007). Impact and the art of motivation maintenance: The effects of contact with beneficiaries on persistence behaviour. Organizational Behaviour and Human Decision Processes, 103, 5367.

Grant, A. M., \& Gino, F. 2010. A little thanks goes a long way: Explaining why gratitude expressions motivate prosocial behaviour. Journal of Personality and Social Psychology, 98, 946-955.

Jenni, K.E., \& Loewenstein, G. (1997). Explaining the "identifiable victim effect". Journal of Risk and Uncertainty, 14, 235-257.

Kashdan, T. B., Biswas-Diener, R., \& King, L. A. (2008). Reconsidering happiness: The costs of distinguishing between hedonics and eudaimonia. Journal of Positive Psychology, 3, 219-233.

Lyubomirsky, S., \& Lepper, H. S. (1999). A measure of subjective happiness: Preliminary reliability and construct validation. Social Indicators Research, 46, 137-155.

Lyubomirsky, S., Sheldon, K. M., \& Schkade, D. (2005). Pursuing happiness: The architecture of sustainable change. Review of General Psychology, 9, 111-131.

Norton, M.I., Mochon, D., \& Ariely, D. (2012). The IKEA effect: When labor leads to love. Journal of Consumer Psychology, 22, 453-460.

Penner, L. A., Dovidio, J. F., Piliavin, J. A., \& Schroeder, D. A. (2005). Prosocial behavior: Multilevel perspectives. Annual Review of Psychology, 56, 365-92. 
Ryan, R. M., \& Deci, E. L. (2000). Self-Determination Theory and the facilitation of intrinsic motivation, social development, and well-being. American Psychologist, 55, 68-78.

Simmons J., Nelson L., \& Simonsohn U. (2011). False-positive psychology: Undisclosed flexibility in data collection and analysis allow presenting anything as significant. Psychological Science, 22, 1359-1366.

Small, D. A., \& Loewenstein, G. (2003). Helping a victim or helping the victim: Altruism and identifiability. Journal of Risk and Uncertainty, 26, 5-16.

Smith, K.D., Keating, J.P., \& Stotland, E. (1989). Altruism reconsidered: The effect of denying feedback on a victim's status to empathic witnesses. Journal of Personality and Social Psychology, 57, 641-650.

Van Boven, L., \& Gilovich, T. (2003). To do or to have? That is the question. Journal of Personality and Social Psychology, 85, 1193-1202.

Watson, D., Clark, L. A., \& Tellegen, A. (1988). Development and validation of brief measures of positive and negative affect: The PANAS scales. Journal of Personality and Social Psychology, 54, 1063-1070.

Weinstein, N., \& Ryan, R. M. (2010). When helping helps: Autonomous motivation for prosocial Behaviour and its influence on well-being for the helper and recipient. Journal of Personality and Social Psychology, 98, 222-244.

White, R. W. (1959). Motivation reconsidered: The concept of competence. Psychological Review, 66, 297-333.

Williamson, G. M., \& Clark, M. S. (1989). Providing help and desired relationship type as determinants of changes in moods and self-evaluations. Journal of Personality and Social Psychology, 56, 722-734. 


\section{Footnote}

${ }^{1}$ Another group of participants was assigned to recall the last time they spent approximately twenty dollars on someone else and report their SWB. This condition was included to determine whether the difference between the prosocial boost and prosocial blocked conditions was driven by elevated well-being in the boost condition, depressed well-being in the blocked condition, or both. Participants in this prosocial recall condition reported well-being levels $(M=-.09, S D=$ .94 ) that did not differ from the personal or prosocial blocked conditions ( $p$ s $>.80$ ), but did differ from the prosocial boost condition $(p<.04)$, indicating that impact information is critical for unleashing the emotional rewards of giving. 
Table 1. Charitable appeals provided in Study 1.

\begin{tabular}{|c|c|}
\hline Organization & Charitable Appeal \\
\hline UNICEF & $\begin{array}{l}\text { Before you make a decision about donating though, you should know } \\
\text { that your donation will be given to the United Nations International } \\
\text { Children's Emergency Fund (UNICEF), which is a charitable } \\
\text { foundation whose work is carried out in } 190 \text { countries around the } \\
\text { world. The heart of UNICEF's work is in the field with some 10,000 } \\
\text { employees working on international priorities such as child } \\
\text { protection, survival and development. }\end{array}$ \\
\hline Spread the Net & $\begin{array}{l}\text { Before you make a decision about donating though, you should know } \\
\text { that your donation will be given to Spread the Net, a subsidiary } \\
\text { branch of the United Nations International Children's Emergency } \\
\text { Fund (UNICEF). This cause was initiated to raise awareness and } \\
\text { help wipe out death by malaria. Every } \$ 10 \text { collected purchases a bed } \\
\text { net for a child in Africa - a simple, effective, inexpensive way to } \\
\text { make a BIG difference - saving lives, one net at a time. }\end{array}$ \\
\hline
\end{tabular}

Note: Charity descriptions were created using language from each charity's website. 
Table 2. Means and standard deviations for the three recollection conditions in Study 2.

\section{Recall Condition}

\begin{tabular}{lccc}
\cline { 2 - 4 } & Prosocial Boost & Prosocial Blocked & Personal \\
\hline Prosocial Impact & $5.04(1.20)^{a}$ & $2.54(1.58)^{b}$ & $1.51(1.09)^{c}$ \\
Subjective Well-Being & $.23(.79)^{a}$ & $-.16(.80)^{b}$ & $-.12(.87)^{b}$ \\
\hline
\end{tabular}

Note: Superscript text denotes significant mean differences. Means with the same superscript are not significantly different from one another at the $p=.05$ level. 


\section{Figure Caption}

Figure 1. Relationship between donation size and happiness in the Spread the Net and UNICEF conditions in Study 1.

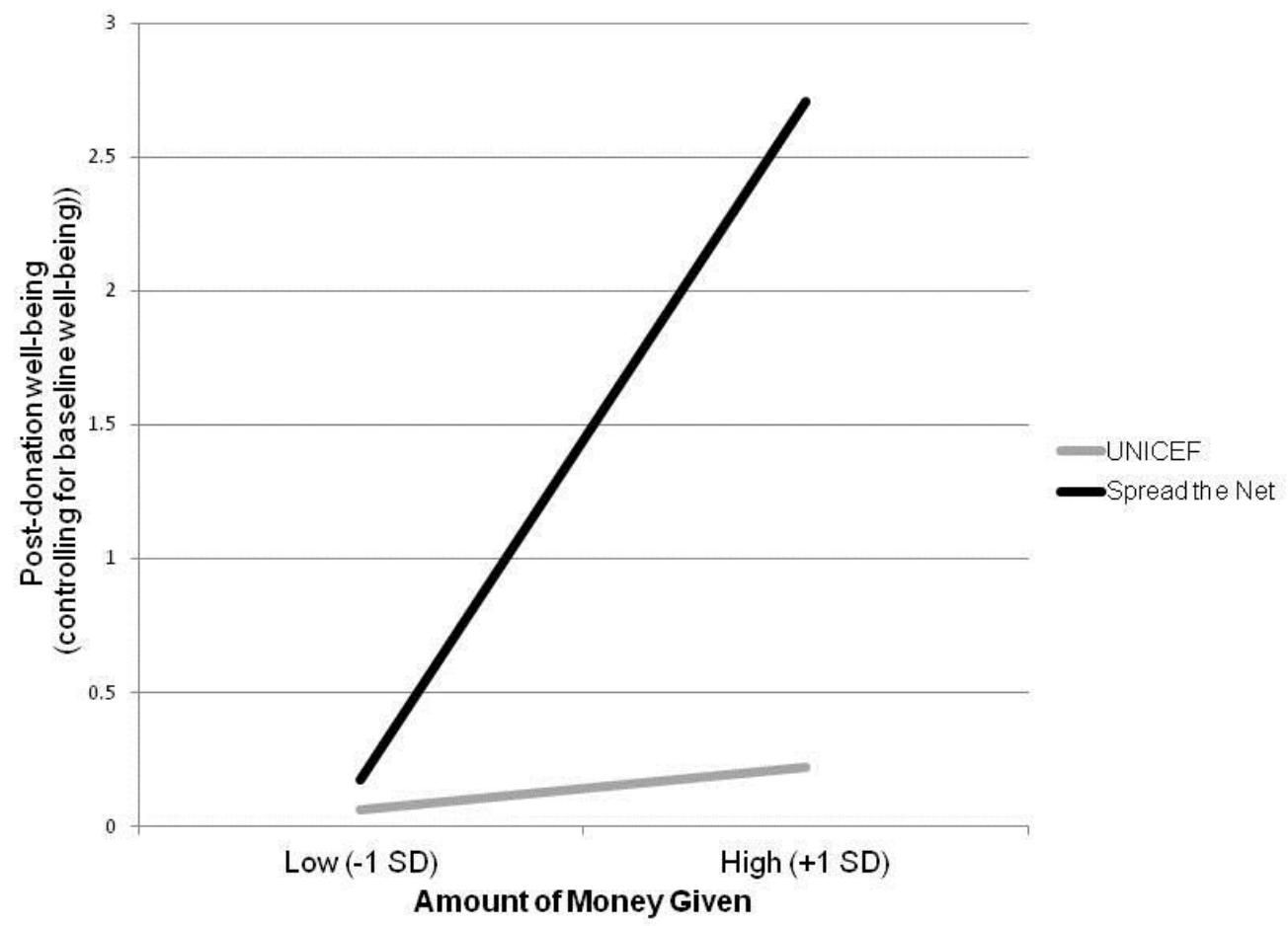

